\title{
Breaking boundaries: optimizing reconsolidation-based interventions for strong and old memories
}

\author{
James W.B. Elsey and Merel Kindt \\ Department of Clinical Psychology, University of Amsterdam, 1018 WB Amsterdam, The Netherlands
}

\begin{abstract}
Recent research has demonstrated that consolidated memories can enter a temporary labile state after reactivation, requiring restabilization in order to persist. This process, known as reconsolidation, potentially allows for the modification and disruption of memory. Much interest in reconsolidation stems from the possibility that maladaptive memory traces-a core feature of several psychiatric conditions-could be tackled by disrupting their reconsolidation. However, research has indicated a range of supposed boundary conditions on the induction of reconsolidation. Stronger memories, often resulting from exposure to stressful conditions, or older memories, appear to be relatively resistant to undergoing reconsolidation. This may be taken as a potential stumbling block for reconsolidation-based interventions: in clinical practice, old and strong maladaptive memories are the norm rather than the exception. Yet, boundary conditions have been derived from limited experimental evidence, are not unique to reconsolidation-based interventions, and do not seem to be absolute. In this paper, we review a range of experimental studies that have aimed to disrupt old memories, or memories that were strengthened by stress manipulations, through reconsolidation. Such research highlights several techniques that could be used to optimize reconsolidation-based approaches and overcome putative boundary conditions. We supplement this review of experimental literature with a case study of a reconsolidation-based treatment of a strong and decades-old phobia for mice, further suggesting that age and strength of memory may not be insurmountable barriers. Translating findings from basic science, to human experiments, to clinical applications and back again, can potentially unlock powerful new treatments for the many people who suffer daily from anxiety disorders.
\end{abstract}

A wealth of evidence in both humans and animals supports the idea that emotional arousal can enhance memory (for review, see McGaugh 2000, 2013). Memories for emotionally significant items or events are typically more robust than for neutral information, whether this is assessed in laboratory tasks or in everyday life (e.g., Brown and Kulik 1977; Cahill et al. 1994). This enhancement of memory is principally mediated by adrenal stress hormones, such as adrenaline and cortisol, ultimately leading to noradrenergic activation of the amygdala and heightened memory consolidation (McGaugh 2004; Roozendaal et al. 2009). Such enhanced learning has clear adaptive benefits, as it means that more important events are generally better remembered. However, the emotional enhancement of memory can also produce unwanted consequences. Most clearly, traumatic events are the precipitating factor in post-traumatic stress disorder (PTSD), resulting in excessively strong emotional memories that continue to exert a negative influence over those suffering from PTSD well after any adaptive value of the memory has passed. Emotionally arousing learning experiences are also believed to play a major role in the development and maintenance of specific phobias and other anxiety disorders (Rachman 1977; Locker et al. 1996; Kindt 2014). It is important to note, however, that learning experiences leading to fears and phobias are not restricted to classical conditioning. Learning histories are often complex, and may involve vicarious learning, receiving information, and combinations of these, as well as other possible means of acquiring fear (Rachman 1977; Kindt 2014).

Although it was once believed that, after being instantiated in the neuronal architecture of the brain, emotional memories are indelible (LeDoux et al. 1989), more recent evidence points to the remarkable malleability of memory. Specifically, it has been found

\section{Corresponding author: m.kindt@uva.nl}

Article is online at http://www.learnmem.org/cgi/doi/10.1101/lm.044156. 116. that while amnestic agents have little effect on memories when administered several hours or days after learning, reactivation of the memory can render it sensitive to amnestic treatments once again. It is suggested that reactivation can return the memory to a labile state, necessitating an active restabilization process in order for it to persist (Przybyslawski and Sara 1997; Nader et al. 2000). This process is known as reconsolidation (Przybyslawski and Sara 1997), and has been demonstrated across a host of animal models and memory types (Nader et al. 2000; Pedreira et al. 2002; Eisenberg et al. 2003), with findings in humans paralleling those in animals (Kindt et al. 2009). Administering amnestic pharmacological agents, such as protein synthesis inhibitors or propranolol, timed to interfere with the putative restabilization of memory after retrieval, can result in long-lasting attenuation of learned responses.

Given that maladaptive emotional memories are a major feature of many anxiety disorders, and that research on memory reconsolidation suggests that emotional memories may be vulnerable to disruption, there is a clear rationale for harnessing reconsolidation for therapeutic purposes. Yet, the translation of experimental findings on reconsolidation to clinical interventions is far from simple (Elsey and Kindt 2017). Some findings challenge the applicability of reconsolidation-based interventions to psychiatric disorders owing to potential boundary conditions on the induction of reconsolidation (Milekic and Alberini 2002). The types of stressful or emotional experiences that lead to pathological anxiety may result in memories that are simply too strong to be modified through reconsolidation. Furthermore, the time taken

(C) 2017 Elsey and Kindt This article is distributed exclusively by Cold Spring Harbor Laboratory Press for the first 12 months after the full-issue publication date (see http://learnmem.cshlp.org/site/misc/terms.xhtml). After 12 months, it is available under a Creative Commons License (Attribution-NonCommercial 4.0 International), as described at http://creativecommons.org/licenses/by-nc/ $4.0 \%$. 
from the onset of an anxiety disorder to seeking treatment is often in the order of years (Christiana et al. 2000; Thompson et al. 2008), at which point a maladaptive memory trace may no longer be susceptible to manipulation. In the following sections we review research investigating these two clinically relevant boundary conditions, focusing on research that has aimed to mimic stressenhanced memory, and remote emotional memory. We highlight ways in which these ostensible boundary conditions have been overcome, and how such findings might inform clinical interventions. In addition, we present a case report in Box 1 to illustrate how a severe and long-lasting phobia for mice (musophobia) can be treated using a reconsolidation-based procedure, furthering the case that the manipulation of old and strong memories is not an intractable problem.

Covering age and strength of memory does not by any means exhaust the potential barriers to effective memory-modifying interventions-a host of other factors may also modulate memory formation, and are likely to have concomitant effects on later memory expression and malleability. Such factors include controllability and predictability regarding the timing, frequency, or intensity of aversive outcomes, with uncontrollable or unpredictable aversive events typically provoking heightened or more generalized threat responses (Seligman 1968; Foa et al. 1992; Grillon et al. 2004; Shankman et al. 2011). Of course, these characteristics are likely to increase the fear response, and may thus partly operate through similar mechanisms to the studies reviewed, though they will not be specifically addressed.

Additionally, it should be noted that although learning experiences themselves play a key role in the etiology and maintenance of anxiety disorders (Mineka and Zinbarg 2006; Kindt 2014), the majority of people will experience some kind of traumatic event in their lives, yet only a minority will go on to develop a PTSD as a consequence, with unbiased estimates suggesting a conditional risk of 9\% following trauma (Kessler et al. 1995, 2005; Breslau et al. 1998). Hence, individual differences must affect how events are responded to and encoded, potentially affecting later memory malleability (Bomyea et al. 2012). Genetic influences have been implicated in risk for developing PTSD after trauma (Bomyea et al. 2012). Regulation of genetic expression may also be an important factor: in both humans and animals, early adversity leads to epigenetic changes that affect glucocorticoid receptor expression, in turn influencing hypothalamic-pituitary-adrenal axis (HPA) responses to stressors (Weaver et al. 2004; McGowan et al. 2009). Finally, at the phenotypic level, personality has a clear relation to fear memory formation and its modification. For example, individuals characterized by high harm avoidance and stress reactivity are poorer at differentiating threat from safety during both initial learning and extinction training than those scoring low on these traits (Gazendam et al. 2015). Individuals with high trait anxiety may also show resistance to extinction (Gazendam et al. 2013) and to the disruption of fear memory reconsolidation (Soeter and Kindt 2013). There is a huge range of open questions regarding how such factors might influence memory malleability.

\section{Boundary conditions are not absolute}

Experiments in humans have demonstrated that emotional memory for a Pavlovian fear conditioning episode can be effectively neutralized by the administration of propranolol either shortly before or after a brief reactivation of the memory (Kindt et al. 2009; Soeter and Kindt 2010, 2011, 2012a,b, 2015a; Sevenster et al. 2012, 2013, 2014; but see Bos et al. 2014; Schroyens et al. 2017). While participants still display declarative memory for the contingencies they previously learned between pictures and electric shocks, startle responses to the CS+ (which track the affective va- lence of stimuli) (Lang et al. 1990) drop to the level of the stimulus that was never reinforced. Consistent with the idea that this experimental manipulation reflects a modification of emotional memory, further studies have shown that participants' subjective distress in response to the CS+ is also reduced as a result of propranolol combined with memory reactivation (Soeter and Kindt 2012b). Animal research has also shown that the systemic effects of propranolol on reconsolidation are achieved by targeting the amygdala (Dẹbiec and LeDoux 2004), and disruption of fear memory reconsolidation is correlated with a reduction of synaptic potentiation in the lateral amygdala selective to the reactivated fear memory (Doyère et al. 2007). Propranolol, a lipophilic $\beta$-adrenergic receptor $(\beta-\mathrm{AR})$ antagonist that crosses the blood-brain barrier, targets $\beta$-ARs in the amygdala. $\beta$-ARs play an essential role in protein synthesis via the canonical downstream $\beta$-AR/PKA/CREB signaling pathway, one of the molecular cascades that regulates the gene transcription and subsequent protein synthesis required for the consolidation and reconsolidation of memory (e.g., Otis et al. 2015), or via other downstream signaling pathways such as ERK/ MAPK (O'Dell et al. 2015; Krawczyk et al. 2016).

Although Pavlovian fear conditioning is a valid and highly informative translational model for the development of anxiety disorders, it is not without limitations (Beckers et al. 2013). Most obviously, the amount of stress that participants experience in a typical fear-conditioning experiment is substantially lower than what occurs in aversive learning experiences in the outside world. However, there are experimental manipulations that can to some extent mimic the effects of real stressors. Yohimbine is an $\alpha_{2}$-adrenergic receptor antagonist, which increases noradrenergic transmission in the brain (Charney et al. 1987; Soeter and Kindt 2011). Participants given yohimbine prior to fear conditioning have been found to display stronger memories $48 \mathrm{~h}$ later when the drug was no longer on board: differential responding to the CS+ relative to the CS- is resistant to extinction and is more easily recovered when extinction is successful (Soeter and Kindt 2011). Participants receiving yohimbine also display greater generalization - a known feature of PTSD - than participants given placebo (Soeter and Kindt 2012b). Despite being resistant to extinction, memories formed under the influence of yohimbine were still susceptible to the amnestic effects of propranolol given in combination with memory reactivation (Soeter and Kindt 2012b). Fearpotentiated startle to the CS+ was neutralized, did not generalize to other CSs, and was not reinstated by unsignaled electrical shocks, in participants receiving propranolol + reactivation. Hence, it would seem that stronger memories formed under stress are somewhat resistant, but may ultimately still be malleable.

This finding is also notable for highlighting divergent results from standard extinction training, relative to a reconsolidationbased approach. Challenges to the utility of reconsolidation-based procedures may reference strength of memory as a boundary condition, but fail to note that resistance to extinction (an experimental model of exposure training - the standard treatment for anxiety disorders) is often the very metric by which memory strength is initially determined. If strength of memory is a challenge for reconsolidation, this is likely the case for extinction as well.

Despite clearly producing stronger memories, such procedures remain quite distant from truly stressful life experiences. Animal research may be of further interest here, given that aversive stimulation administered in fear conditioning with rodents is genuinely threatening. Rats given systemic yohimbine either after acquisition or reactivation of contextual fear conditioning displayed greater freezing at later testing, as well as more generalization, than rats given saline (Gazarini et al. 2013). In contrast to Soeter and Kindts' (2012b) findings, and consistent with the idea that stronger memories formed under stressful conditions might be more resistant to manipulation, it has been found that yohimbine- 
Overcoming boundary conditions on reconsolidation

BOX 1. A reconsolidation-based treatment of a decade-old fear memory

\section{Case history and diagnosis}

Eva, a woman in her 40s, contacted us for help tackling her long-term and severe fear of mice. When very young she had not been afraid of mice, but around $11 \mathrm{yr}$ of age she had been in her bedroom with her mother. Her mother was kneeling on the floor, sewing Eva a dress, when three mice ran out from under the bed and across Eva's feet, at which point her mother became hysterical. Though Eva had not been particularly afraid of the mice when this happened and already knew of her mother's fear, her mother's reaction had shocked her. She described that her fear developed after this experience and became increasingly intense.

Eva's fear was excessive. Most recently, her husband had organized a business trip. Eva planned to stay somewhere else before the trip was cancelled. Normal precautions to prevent mice from entering Eva's house, including filling in holes and laying poison or traps were taken. However, she also tried to avoid or not pay attention to areas where she had seen mice, and after recent encounters with mice would keep a pair of tall, heavy boots by her bed, covered with material to prevent mice getting in. If she needed to leave the bed at night the boots ensured no mice could contact her feet, and she could stomp loudly to make sure they would avoid her. She had tried cognitive therapy 10 yr previously, and an eye-movement desensitization and reprocessing (EMDR)-based therapy $3 \mathrm{yr}$ ago, neither of which significantly reduced her fear. Other than Eva's fear of mice, she was physically and mentally healthy. We made a diagnosis of specific phobia based on the structured clinical interview for DSM disorders (SCID), and noted more specifically "musophobia" (phobia for mice).

\section{Reconsolidation-based intervention}

The treatment focused on reactivating the core of Eva's fear: being in an enclosed area where a mouse could run over her feet. We placed a brown mouse in a $2 \times 2-\mathrm{m}$ enclosure, with walls $50 \mathrm{~cm}$ high. The therapist began the treatment session by talking with Eva about her fear and asking her to recall early or particularly intense experiences she had had with mice. It was then explained that in another room, we had an enclosure with a mouse inside it, and that Eva would be asked to approach the enclosure, in her bare feet, and step inside. If Eva's fear was sufficiently reactivated, we did not intend to actually enter the enclosure, but we had this as an option should the mouse fail to provoke her fear with her standing outside.

Upon seeing the mouse in the enclosure, Eva became very clearly distressed. When asked what she would fear most if she entered the enclosure, she began to cry and clutch herself. She said she would be most afraid of the mouse coming toward her and feeling its feet and tail on her. After asking Eva to focus on the feelings in her body and to look at the mouse, we lead her from the room without actually stepping in to the box. In total, the reactivation lasted $2 \frac{1}{4} \mathrm{~min}$, with Eva crying for most of this time. Afterwards, Eva was taken to another room and given a $40 \mathrm{mg}$ pill of propranolol, then allowed to relax quietly on her own with a book for an hour before we closed the session.

At the follow-up 1 mo later, Eva reported that she was not sure whether her fear had changed because she had not been exposed to any mice. As can be seen in her questionnaire responses (Fig. 1), she still reported avoidance of mice and engagement in behaviors that interfered with her daily life, though she appeared to have experienced somewhat less anxiety over the previous week relative to the week before the treatment session. Upon being exposed to the mouse, Eva noted a strange difference in her feelings, saying: "Very weird...I know I am afraid of mice, but do not feel it, only a little in my legs." Eva was then able to step into the enclosure, though she tried to make the mouse go away when it approached her. The therapist joined her in the enclosure to help test whether she could now interact with mice differently, through demonstrating some interactions and conducting some tests of her fear. Eva touched the mouse within 5 min of entering the room (seconds after being asked), held it in her hands a minute later, had it walking across her bare feet 5 min after that, put it in her clothes after another 5 min, then on her back and ultimately on her head within another $5 \mathrm{~min}$. Commenting on the experience, Eva said: "This is so bizarre, absolutely different." She noted that some anxiety had come up during these new experiences, but that it was not dramatic or intense like before. Though the therapist certainly guided Eva and modeled behavior with the mouse, the rapidity of the transformation in her fear behavior makes a pure exposure effect of session 2, or indeed an exposure effect of session 1, seem implausible. Even single session exposure training typically lasts at least $2 \mathrm{~h}$ (Öst, 1989; Zlomke and Davis 2008), and Eva noted a difference in her emotional response to the mouse before the therapist performed any demonstrations.

Ten days after the follow-up session, Eva's anxiety levels over the previous week had dropped further relative to before the treatment, and she reported less interference with her daily life from the phobia, but she was still uncertain how she might react if she encountered a mouse suddenly at home. Twenty-four days after the follow-up session, Eva's fear had stayed low and she now reported no avoidance or interference with her daily life due to mice. She had been woken up at night by the sounds of mice near her bed. Rather than putting on her boots and asking her husband to deal with the situation, she had walked barefoot to the bathroom, and then simply gone back to sleep. Eva returned to the laboratory $\sim 3$ mo later and reported that her fear had remained low. When exposed to the mouse again, she was able to pick it up and have it on her feet without any aid from the therapist. Seeing how she lived now and looking back on her old behaviors, she reported that she had probably underreported how much the phobia interfered with her daily life, and felt that it had been a major burden she was now rid of.

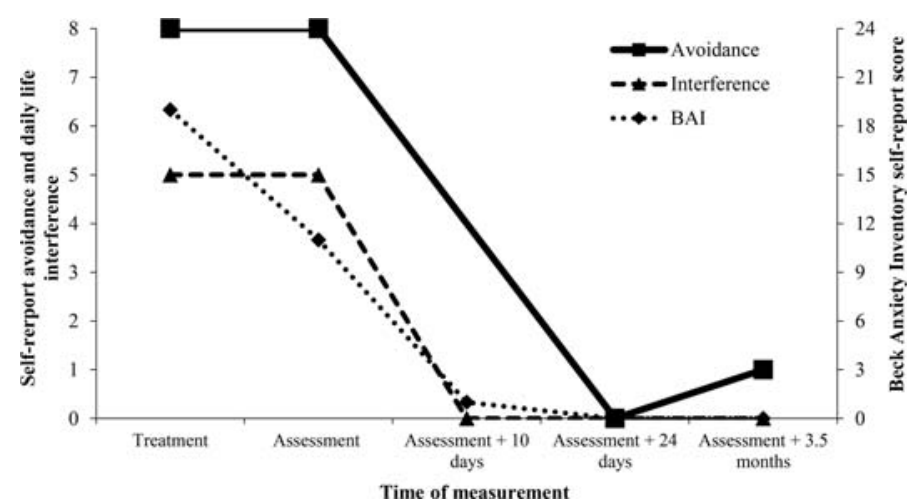

Figure 1. Changes in severity of phobia over time 
potentiated contextual fear memories were not disrupted by the administration of clonidine or cannabidiol following reactivation (these drugs did disrupt contextual fear memories learned without yohimbine) (Gazarini et al. 2015).

However, the potential boundary condition imposed by enhanced memory was not absolute. In order for disruptive effects of amnestic agents to be observed, it is necessary for the target memory to enter a labile state. NMDA receptor activation in the amygdala is thought to be vital for labilization to occur in fear memory (Mamou et al. 2006; Bustos et al. 2010), and can be increased by administration of the partial NMDA agonist D-cycloserine (DCS). The amnestic effects of post-reactivation clonidine and cannabidiol were restored when DCS was given to rats prior to memory retrieval (Gazarini et al. 2015). Work using nonpharmacological stressors supports these findings. Bustos et al. (2010) found that subjecting rats to stressful immobilization in a brightly lit chamber prior to contextual fear conditioning lead to a memory that was resistant to disruptive effects of even quite high doses of midazolam after reactivation. Yet, DCS administered prior to reactivation rendered the stress-enhanced memory vulnerable to postreactivation midazolam, even in 7-d-old memories. These results were expanded upon with the demonstration that prior stress reduced the reactivation-induced expression of GluN2B subunits of the NMDA receptor in the basolateral amygdala, thought to index destabilization (Mamou et al. 2006; Bustos et al. 2010), and of Zif-268, necessary for memory restabilization (Espejo et al. 2016). It would therefore seem that stress prior to initial learning reduces the likelihood that subsequently reactivated memory will be destabilized, but that this can be reversed by the administration of DCS.

Other manipulations of memory strength might also be considered. Beyond stress, stronger training can be expected to yield stronger memories. Wang et al. (2009) first trained rats with either a strong (10 tone-shock pairings) or weak (1 tone-shock pairing) protocol, and found that the strong memory was more resistant to extinction than the weak memory. In addition, protein synthesis inhibitor anisomycin infused into the lateral and basal nuclei of the amygdala (LBA) following reactivation of memories $2 \mathrm{~d}$ after training was only able to produce amnesia in weakly trained rats. Despite this initial resistance to reconsolidation-based disruption, it was found that the memory could be disrupted by anisomycin when reactivated 30 or $60 \mathrm{~d}$ after strong training. Intriguingly, strong training was found to down-regulate expression of GluN2B. This down-regulation of GluN2B varied with the susceptibility of the memory to reconsolidation blockade, again indicating a key role of NMDA receptors in labilization of memory (Mamou et al. 2006). In an interesting parallel using morphine conditioned place preference, Robinson and Franklin (2010) similarly found that strongly trained memories were impervious to the amnestic effects of both midazolam and propranolol in the days following the final training trial, but were vulnerable when reactivated $30 \mathrm{~d}$ after training.

Research outside of fear memory might also elucidate some ways of overcoming the strength of memory as a boundary on reconsolidation. For example, Winters et al. (2009) found that strong training for object recognition memory resulted in a memory that was resistant to amnestic interventions. However, reactivating the memory in the presence of a novel contextual change could circumvent this limitation. Such findings align with more recent research in both humans and animals that indicates some kind of novelty during reactivation, operationalized as a prediction error or mismatch between what has been learned and what occurs during reactivation, is necessary for the induction of reconsolidation (Pedreira et al. 2004; Morris et al. 2006; Sevenster et al. 2013, 2014; Alfei et al. 2015). Thus, in addition to the possibility of pharmacologically manipulating the malleability of memory, it also seems that the parameters of the reactivation session deter- mine whether a memory will be made vulnerable to an intervention. This possibility will be returned to in the following discussion of memory age as a boundary condition for the induction of memory reconsolidation.

As noted above, some research suggests that older memories may actually be more vulnerable to reconsolidation-based manipulations, but a general assumption has been that the passage of time promotes memory stability (McGaugh, 2000) and may hinder attempts at triggering reconsolidation (Milekic and Alberini 2002). Early studies indicated that reconsolidation is not triggered when old memories are reactivated. For example, Milekic and Alberini (2002) trained rats on an inhibitory avoidance task, and then reactivated their memories 2, 7, 14, and 28 d later. Subcutaneous injections of anisomycin after reactivation were found to produce later amnesia in 2-d-old memories, slightly less amnesia in 7-d-old memories, and had no effect on 14- and 28-d-old memories. These findings were corroborated in a later study by the same research group (Inda et al. 2011). A similar temporal gradient in amnestic effects of choline reuptake inhibitor hemicholinium was found by Boccia et al. (2006) in an inhibitory avoidance paradigm with mice. Likewise, Eisenberg and Dudai (2004) conducted Pavlovian fear conditioning in medaka fish and found that the effects of post-reactivation amnestic interventions decreased with time from initial learning.

From these studies it might be concluded that the passage of time represents a strong boundary condition on the induction of reconsolidation, but it should be emphasized that they typically only assessed one way of reactivating the memory. Further research has demonstrated that modifying parameters of the reactivation session may induce reconsolidation in old memories. In the first study to show this, Suzuki et al. (2004) used a contextual fearconditioning paradigm in mice. As would be expected from the previous studies of inhibitory avoidance, it was found that a brief reactivation of $3 \mathrm{~min}$ rendered contextual fear memories vulnerable to disruption by anisomycin, but only if the reactivation occurred up to $3 \mathrm{wk}$ after learning. Anisomycin had no such effect when memories were reactivated in the same fashion $8 \mathrm{wk}$ after learning. However, if the time of reactivation was extended to 10 min, then the 8-wk-old memory was again susceptible to the amnestic effects of anisomycin. This same extension of the reactivation was also found to trigger reconsolidation of strongly trained memories that were otherwise impervious to disruption. One possibility is that memories for the temporal relationship between a stimulus and an anticipated aversive become less specific or precise over time, necessitating a more unambiguous disconfirmation (i.e., lack of reinforcement for a longer time period) in order for reconsolidation to be triggered.

In a follow-up experiment, Frankland et al. (2006) found that targeting anisomycin delivery at dorsal hippocampal sites blocked recent, but not 36-d-old memories. It has been suggested that systems consolidation-a process by which different brain sites become responsible for the retrieval or storage of memories over time-may explain such findings (Frankland et al. 2006). If memory engrams become distributed over different brain regions with the passage of time, then they may become more resistant to disruption if the drug is locally injected at brain sites with only a temporary role in memory storage or retrieval. However, both lesion (Gale et al. 2004) and optogenetic (Kitamura et al. 2017) approaches suggest that the basolateral amygdala retains a role in fear memory expression for both recent and remote memories, even if the role of hippocampal neurons is time dependent. When Frankland et al. (2006) administered anisomycin systemically after memory reactivation, allowing protein synthesis to be inhibited in brain regions other than the hippocampus (such as the amygdala), later memory expression even for old memories was significantly impaired. 
The suggestion that altering parameters of the reactivation session could result in destabilization of remote memories has also been supported in a study of contextual fear conditioning in rats. Bustos et al. (2009) systematically investigated the effect of varying reactivation length and midazolam dosage on contextual fear memory reconsolidation. Firstly, they found that 3-min reactivation was sufficient to trigger reconsolidation in recent (1-d old) memories, an extended reactivation of $5 \mathrm{~min}$ was necessary for the observation of midazolam's disruptive effects in 21-d-old memories. For 36-d-old memories, a 5-min reactivation combined with an increased dose of midazolam ( $3 \mathrm{mg} / \mathrm{kg}$ versus $1.5 \mathrm{mg} / \mathrm{kg}$ ) was sufficient for the blockade of reconsolidation.

In summary, current evidence provides support for the idea that stronger (e.g., stress-enhanced) and older memories are generally more resistant to undergoing reconsolidation, and for this reconsolidation to be disrupted. However, studies claiming strict boundary conditions of age and strength of memory have typically been limited by only assessing a small range of possible reactivation procedures and other means of labilizing the memory trace. Several options are available to researchers, and perhaps ultimately clinicians, seeking to trigger and disrupt memory reconsolidation. A selection of these techniques is presented in Table 1, and discussed further in the Summary. Changing parameters of the reactivation session, dosage of amnestic agent, or even utilizing a pharmacological agent that serves to aid in the labilization of memory are all open possibilities. While older and stronger memories may present a challenge to the utilization of reconsolidationbased treatments in clinical settings, current evidence suggests that we should not simply write-off this promising possibility in light of limited experimental research. It bears mentioning that research on disrupting memory reconsolidation for stronger and older memories in humans has only just begun. As an example, Box 1 presents an illustrative case study, in which a strong and decades-old fear memory-a specific phobia for mice (musophobia) that the patient believes evolved following a stressful event -was tackled using a reconsolidation-based procedure.

\section{Synthesis and discussion}

Stressful learning experiences can induce particularly strong memories and are thought to play a major role in the development of numerous anxiety disorders. People who develop mental health problems following stressful events may take many years before seeking treatment. Human and animal research into the malleability of memory suggests that older and stronger memories can be resistant to disruption through reconsolidation. These findings have been seen as a serious threat to the clinical utility of reconsolidation-based procedures: strong and longstanding maladaptive memories are the norm, rather than the exception, in clinical practice. However, such conclusions have typically been drawn based upon limited attempts at varying reactivation procedures or other factors that may help trigger reconsolidation (Wang et al. 2009). Research into human and animal models of stress-enhanced learning, as well as studies of old memories, highlight a range of techniques that may prove fruitful for inducing memory destabilization, or aid in the disruption of restabilization, even in old and strong memories (summarized in Table 1). Researchers have found that extending the length of reactivation, including novelty or prediction error during reactivation, altering drug dosages, and even utilizing pharmacological means to promote memory destabilization, are potential ways of tackling memories that are resistant to manipulation, and could be investigated in clinically informative human studies.

When translating such insights into clinical practice, some limitations or potential drawbacks should be considered. Notably, it may not always be possible to combine the different techniques. Regarding the utilization of DCS as a means of aiding the destabilization of memories, research into DCS as an extinction-enhancing agent suggests that this may be a one-time opportunity (Langton and Richardson 2008). Although it is unknown whether this is the case for its use in reconsolidation, multiple treatment sessions combining DCS with a reconsolidationdisrupting agent might not be feasible. Additionally, when the putative restabilization process following memory labilization is not disrupted, DCS could enhance fear memory (Lee et al. 2006). Hence, when the disruption of reconsolidation is not successful, or when placebo controls for the reconsolidation-disrupting agent are used, fear responding might be enhanced. More generally, combinations of drugs or higher doses may be less well tolerated by human subjects, or difficult to approve for testing.

Regarding the exploration of behavioral parameters, such as the length of reactivation or the incorporation of novelty/prediction error into the reactivation, it is not yet possible to make clear

Table 1. Techniques for tackling maladaptive memories

\begin{tabular}{|c|c|c|}
\hline Technique & Example studies with model organism, memory type, and amnestic agent & Potential drawbacks \\
\hline $\begin{array}{l}\text { Extended } \\
\text { reactivation trials }\end{array}$ & $\begin{array}{l}\text { Sevenster et al. (2014). Humans. Pavlovian fear conditioning. Propranolol. } \\
\text { Suzuki et al. (2004). Mice. Contextual fear conditioning. Anisomycin. } \\
\text { Bustos et al. (2009). Rats. Contextual fear conditioning. Midazolam. }\end{array}$ & $\begin{array}{l}\text { Longer sessions risk initiating extinction, or } \\
\text { a transient state in between } \\
\text { reconsolidation and extinction (Merlo } \\
\text { et al. 2014), precluding the disruption } \\
\text { of reconsolidation. }\end{array}$ \\
\hline $\begin{array}{l}\text { Multiple treatment } \\
\text { sessions }\end{array}$ & $\begin{array}{l}\text { This option is self-evident. If treatment is unsuccessful it may be possible to } \\
\text { reactivate the memory in a different way and attempt a second intervention. } \\
\text { If treatment is partially successful then further treatment sessions may increase } \\
\text { the benefit. }\end{array}$ & $\begin{array}{l}\text { Patients may struggle with multiple } \\
\text { intensely emotional sessions. }\end{array}$ \\
\hline $\begin{array}{l}\text { Pharmacological } \\
\text { labilization }\end{array}$ & $\begin{array}{l}\text { Bustos et al. (2010). Rats. Contextual fear conditioning. D-cycloserine + } \\
\text { Midazolam. } \\
\text { Gazarini et al. (2015). Rats. Contextual fear conditioning. D-cycloserine }+ \\
\text { clonidine or cannabidiol. }\end{array}$ & $\begin{array}{l}\text { DCS and propranolol have no known } \\
\text { interactions, but may be difficult to } \\
\text { approve in human subjects. Facilitation } \\
\text { with DCS may be a one-time } \\
\text { opportunity (Langton and Richardson } \\
\text { 2008). }\end{array}$ \\
\hline $\begin{array}{l}\text { Including prediction } \\
\text { error or novelty }\end{array}$ & $\begin{array}{l}\text { Winters et al. (2009). Object memory. Rats. MK-801. } \\
\text { Sevenster et al. (2013). Pavlovian fear conditioning. Humans. Propranolol. } \\
\text { Alfei et al. (2015). Contextual fear conditioning. Rats. Midazolam. }\end{array}$ & $\begin{array}{l}\text { Determining the optimal circumstances for } \\
\text { a prediction error or novel experience is } \\
\text { more difficult in clinical practice than } \\
\text { experimental research. }\end{array}$ \\
\hline Altering dosages & Bustos et al. (2009). Rats. Contextual fear conditioning. Midazolam. & $\begin{array}{l}\text { Higher doses may be less well tolerated in } \\
\text { human subjects. }\end{array}$ \\
\hline
\end{tabular}


recommendations for clinical practice. Brief, single violations of expectations trigger reconsolidation, whereas multiple or extended prediction errors can produce extinction (Morris et al. 2006; Sevenster et al. 2014; Alfei et al. 2015). A third "limbo" period, in between the induction of either reconsolidation or extinction, also appears to exist and equally precludes the disruption of reconsolidation (Merlo et al. 2014; Sevenster et al. 2014). While prediction errors can be carefully controlled in experimental studies and designed to directly violate what was learned during memory formation, this is clearly not so easy for clinical conditions. Optimal reactivation conditions are likely to vary according to individual temperament and learning history. For example, longer reactivations or clearer violations of expectations have been found to be necessary for extinction to occur in high trait anxious individuals (Gazendam et al. 2013, 2015), and this might also be the case for triggering reconsolidation (Soeter and Kindt 2013).

These potential difficulties are far from decisive impasses, however, and point to the vast range of open questions and research opportunities regarding the translation of experimental research on reconsolidation into clinical interventions. There is great value in exploratory clinical work aimed at gleaning insights into how best to perform memory reactivation sessions in a wide range of clinical cases, even if these do not conform to the gold standard of a randomized controlled trial. Certainly, uncontrolled trials and case studies alone are insufficient for demonstrating the therapeutic potential of reconsolidation-based procedures, as they cannot rule out factors such as placebo effects, or convincingly demonstrate that reconsolidation is the best explanation for the observed treatment effect. However, simply assigning participants to receive either an amnestic agent or a placebo, and exposing them to a single, standardized reactivation procedure may not always be the most informative approach. A negative result leaves open the possibility that alternative means of reactivation would have been more effective. After failed attempts at disrupting reconsolidation, it may be prudent to investigate a range of reactivation procedures, rather than prematurely concluding either that reconsolidationbased procedures simply do not work, or suggesting the use of new amnestic agents.

This raises some issues, as it makes the general hypothesis that the disruption of memory reconsolidation can be used to tackle clinical disorders essentially unfalsifiable: there are always more ways that a memory could have been reactivated (Popper 1963). Researchers can nevertheless design principled variations of reactivation procedures to determine the conditions under which memory modification is observed. If reconsolidation is to be claimed as the underlying mechanism of this modification of memory, then such exploratory work should form part of a broader researcher program to assess whether outcomes are consistent with reconsolidation (JWB Elsey, VA Van Ast, M Kindt, unpubl.). Other techniques described in this review, such as pharmacological labilization, are also open to investigation. If continued efforts at varying reactivation procedures and using other experimentally informed techniques fail to result in effective clinical interventions, then this would represent a clear blow to the idea that reconsolidation-based approaches can be utilized in a therapeutic context, despite not definitively refuting the possibility. However, even without taking advantage of all the potential means of enhancing memory destabilization and disruption, reconsolidation-based interventions have already demonstrated utility in the alleviation of anxiety and fear.

In a randomized, double blind, placebo-controlled trial, Soeter and Kindt (2015b) found that administering propranolol after exposure to a fear-provoking tarantula led to a dramatic reduction in later fear responses to spiders in a sample of highly spider-fearful individuals. Though most of this sample would have been judged as subclinical due to having relatively little daily life interference, their fear was strong and had been present for many years-in most cases as long as participants could remember. We here supplemented these findings with a demonstration that a similar procedure could be used to alleviate a clinically significant fear of mice, which evolved as a result of a stressful experience, which the patient had been troubled by for decades, and experienced significant daily life interference from (Box 1).

Additional research combining propranolol with reactivation of traumatic memories suggests that this reconsolidation-based approach may even be effective in more extreme cases of stressinduced pathology such as PTSD (Brunet et al. 2008; Kindt and Van Emmerik 2016), though results have not been entirely consistent (Wood et al. 2015). It should be emphasized that just like PTSD, phobias can be a terrible burden for those suffering from them and, despite being something of a "poster-child" for the success of psychological therapies, are far from a solved problem (Becker et al. 2007). Novel treatments for phobias are an end in themselves, as well as being a potential stepping-stone to trauma-related disorders or a "proof of concept."

\section{Conclusion}

Stress can generate strong and long-lasting pathological memories. Such strong, long-term memories have been put forward as a major challenge for reconsolidation-based interventions, yet there is clear evidence that proposed boundary conditions on reconsolidation may not be absolute: reconsolidation-based approaches are already starting to demonstrate utility in the reduction of anxiety and fear, and a range of techniques for optimizing reconsolidationbased approaches that we outlined in this review may help even further. Translating findings from basic science, to human experiments, to clinical interventions and back again, can potentially unlock powerful new treatments for the many people who suffer daily from anxiety disorders.

\section{Acknowledgments}

We would like to express our thanks to Floris Linnebank for conducting the treatment with J.W.B.E. and to our patient for agreeing to have her case described in this publication.

\section{References}

Alfei JM, Ferrer Monti RI, Molina VA, Bueno AM, Urcelay GP. 2015. Prediction error and trace dominance determine the fate of fear memories after post-training manipulations. Learn Mem 22: 385-400.

Becker ES, Rinck M, Türke V, Kause P, Goodwin R, Neumer S, Margraf J. 2007. Epidemiology of specific phobia subtypes: findings from the Dresden Mental Health Study. Eur Psychiatry 22: 69-74.

Beckers T, Krypotos AM, Boddez Y, Effting M, Kindt M. 2013. What's wrong with fear conditioning? Biol Psychol 92: 90-96.

Boccia MM, Blake MG, Acosta GB, Baratti CM. 2006. Post-retrieval effects of icv infusions of hemicholinium in mice are dependent on the age of the original memory. Learn Mem 13: 376-381.

Bomyea J, Risbrough V, Lang AJ. 2012. A consideration of select pre-trauma factors as key vulnerabilities in PTSD. Clin Psychol Rev 32: 630-641.

Bos MGN, Beckers T, Kindt M. 2014. Noradrenergic blockade of memory reconsolidation: a failure to reduce conditioned fear responding. Front Behav Neurosci 8: 412.

Breslau N, Kessler RC, Chilcoat HD, Schultz LR, Davis GC, Andreski P. 1998. Trauma and posttraumatic stress disorder in the community: the 1996 Detroit area survey of trauma. Arch Gen Psychiatry 55: 626-632.

Brown R, Kulik J. 1977. Flashbulb memories. Cognition 5: 73-99.

Brunet A, Orr SP, Tremblay J, Robertson K, Nader K, Pitman RK. 2008. Effect of post-retrieval propranolol on psychophysiologic responding during subsequent script-driven traumatic imagery in post-traumatic stress disorder. J Psychiatr Res 42: 503-506.

Bustos SG, Maldonado H, Molina VA. 2009. Disruptive effect of Midazolam on fear memory reconsolidation: decisive influence of reactivation time span and memory age. Neuropsychopharmacology 34: 446-457.

Bustos SG, Giachero M, Maldonado H, Molina VA. 2010. Previous stress attenuates the susceptibility to midazolam's disruptive effect on fear 
memory reconsolidation: influence of pre-reactivation D-cycloserine administration. Neuropsychopharmacology 35: 1097-1108.

Cahill L, Prins B, Weber M, McGaugh JL. 1994. $\beta$-Adrenergic activation and memory for emotional events. Nature 371: 702-704.

Charney DS, Woods SW, Goodman WK, Heninger GR. 1987. Neurobiological mechanisms of panic anxiety: biochemical and behavioral correlates of yohimbine-induced panic attacks. Am J Psychiatry 144: 1030-1036.

Christiana JM, Gilman SE, Guardino M, Mickelson K, Morselli PL, Olfson M, Kessler RC. 2000. Duration between onset and time of obtaining initial treatment among people with anxiety and mood disorders: an international survey of members of mental health patient advocate groups. Psychol Med 30: 693-703.

Debiec J, Ledoux JE. 2004. Disruption of reconsolidation but not consolidation of auditory fear conditioning by noradrenergic blockade in the amygdala. Neuroscience 129: 267-272.

Doyère V, Dẹbiec J, Monfils M, Schafe GE, LeDoux JE. 2007. Synapse-specific reconsolidation of distinct fear memories in the lateral amygdala. Nat Neurosci 10: 414-416.

Eisenberg M, Dudai Y. 2004. Reconsolidation of fresh, remote, and extinguished fear memory in medaka: old fears don't die. Eur J Neurosci 20: $3397-3403$.

Eisenberg M, Kobilo T, Berman DE, Dudai Y. 2003. Stability of retrieved memory: inverse correlation with trace dominance. Science 301: $1102-1104$.

Elsey JWB, Kindt M. 2017. Tackling maladaptive memories through reconsolidation: from neural to clinical science. Neurobiol Learn Mem 142: $108-117$.

Espejo PJ, Ortiz V, Martijena ID, Molina VA. 2016. Stress-induced resistance to the fear memory labilization/reconsolidation process. involvement of the basolateral amygdala complex. Neuropharmacology 109: $349-356$

Foa EB, Zinbarg R, Rothbaum BO. 1992. Uncontrollability and unpredictability in post-traumatic stress disorder: an animal model. Psychol Bull 112: 218.

Frankland PW, Ding H, Takahashi E, Suzuki A, Kida S, Silva AJ. 2006. Stability of recent and remote contextual fear memory. Learn Mem 13: 451-457.

Gale GD, Anagnostaras SG, Godsil BP, Mitchell S, Nozawa T, Sage JR, Wiltgen B, Fanselow MS. 2004. Role of the basolateral amygdala in the storage of fear memories across the adult lifetime of rats. J Neurosci 24: $3810-3815$.

Gazarini L, Stern CAJ, Carobrez AP, Bertoglio LJ. 2013. Enhanced noradrenergic activity potentiates fear memory consolidation and reconsolidation by differentially recruiting $\alpha 1$ - and $\beta$-adrenergic receptors. Learn Mem 20: 210-219.

Gazarini L, Stern CA, Piornedo RR, Takahashi RN, Bertoglio LJ. 2015. PTSD-like memory generated through enhanced noradrenergic activity is mitigated by a dual step pharmacological intervention targeting its reconsolidation. Int I Neuropsychopharmacol 18: pyu026.

Gazendam FJ, Kamphuis JH, Kindt M. 2013. Deficient safety learning characterizes high trait anxious individuals. Biol Psychol 92: 342-352

Gazendam FJ, Kamphuis JH, Eigenhuis A, Huizenga HM, Soeter M, Bos MG, Sevenster D, Kindt M. 2015. Personality predicts individual variation in fear learning a multilevel growth modeling approach. Clin Psychol Sci 3: 175-188.

Grillon C, Baas JP, Lissek S, Smith K, Milstein J. 2004. Anxious responses to predictable and unpredictable aversive events. Behav Neurosci 118: 916.

Inda MC, Muravieva EV, Alberini CM. 2011. Memory retrieval and the passage of time: from reconsolidation and strengthening to extinction. J Neurosci 31: 1635-1643.

Kessler RC, Sonnega A, Bromet E, Hughes M, Nelson CB. 1995. Posttraumatic stress disorder in the national comorbidity survey. Arch Gen Psychiatry 52: 1048-1060.

Kessler RC, Chiu WT, Demler O, Walters EE. 2005. Prevalence, severity, and comorbidity of 12-month DSM-IV disorders in the national comorbidity survey replication. Arch Gen Psychiatry 62: 617-627.

Kindt M. 2014. A behavioural neuroscience perspective on the aetiology and treatment of anxiety disorders. Behav Res Ther 62: 24-36.

Kindt M, van Emmerik A. 2016. New avenues for treating emotional memory disorders: towards a reconsolidation intervention for posttraumatic stress disorder. Ther Adv Psychopharmacol 6: 283-295.

Kindt M, Soeter M, Vervliet B. 2009. Beyond extinction: erasing human fear responses and preventing the return of fear. Nat Neurosci 12: 256-258.

Kitamura T, Ogawa SK, Roy DS, Okuyama T, Morrissey MD, Smith LM, Redondo RL, Tonegawa S. 2017. Engrams and circuits crucial for systems consolidation of a memory. Science 356: 73-78.

Krawczyk MC, Navarro N, Blake MG, Romano A, Feld M, Boccia MM. 2016. Reconsolidation-induced memory persistence: participation of late phase hippocampal ERK activation. Neurobiol Learn Mem 133: 79-88.
Lang PJ, Bradley MM, Cuthbert BN. 1990. Emotion, attention, and the startle reflex. Psychol Rev 97: 377-395.

Langton JM, Richardson R. 2008. D-cycloserine facilitates extinction the first time but not the second time: an examination of the role of NMDA across the course of repeated extinction sessions. Neuropsychopharmacology 33: 3096-3102.

LeDoux JE, Romanski L, Xagoraris A. 1989. Indelibility of subcortical emotional memories. J Cogn Neurosci 1: 238-243.

Lee JL, Milton AL, Everitt BJ. 2006. Reconsolidation and extinction of conditioned fear: inhibition and potentiation. J Neurosci 26: 10051-10056.

Locker D, Shapiro D, Liddell A. 1996. Negative dental experiences and their relationship to dental anxiety. Community Dent Health 13: 86-92.

Mamou CB, Gamache K, Nader K. 2006. NMDA receptors are critical for unleashing consolidated auditory fear memories. Nat Neurosci 9: $1237-1239$.

McGaugh JL. 2000. Memory-a century of consolidation. Science 287: $248-251$.

McGaugh JL. 2004. The amygdala modulates the consolidation of memories of emotionally arousing experiences. Annu Rev Neurosci 27: 1-28.

McGaugh JL. 2013. Making lasting memories: remembering the significant. Proc Natl Acad Sci 110: 10402-10407.

McGowan PO, Sasaki A, D’alessio AC, Dymov S, Labont B, Szyf M, Turecki G, Meaney MJ. 2009. Epigenetic regulation of the glucocorticoid receptor in human brain associates with childhood abuse. Nat Neurosci 12: $342-348$.

Merlo E, Milton AL, Goozée ZY, Theobald DE, Everitt BJ. 2014. Reconsolidation and extinction are dissociable and mutually exclusive processes: behavioral and molecular evidence. J Neurosci 34: 2422-2431.

Milekic MH, Alberini CM. 2002. Temporally graded requirement for protein synthesis following memory reactivation. Neuron 36: 521-525.

Mineka S, Zinbarg R. 2006. A contemporary learning theory perspective on the etiology of anxiety disorders: it's not what you thought it was. Am Psychol 61: 10.

Morris RG, Inglis J, Ainge JA, Olverman HJ, Tulloch J, Dudai Y, Kelly PA. 2006. Memory reconsolidation: sensitivity of spatial memory to inhibition of protein synthesis in dorsal hippocampus during encoding and retrieval. Neuron 50: 479-489.

Nader K, Schafe GE, Le Doux JE. 2000. Fear memories require protein synthesis in the amygdala for reconsolidation after retrieval. Nature $\mathbf{4 0 6}$ : 722-726.

O'Dell TJ, Connor SA, Guglietta R, Nguyen PV. 2015. $\beta$-adrenergic receptor signaling and modulation of long-term potentiation in the mammalian hippocampus. Learn Mem 22: 461-471.

Öst L. 1989. One-session treatment for specific phobias. Behav Res Ther 27: $1-7$.

Otis JM, Werner CT, Mueller D. 2015. Noradrenergic regulation of fear and drug-associated memory reconsolidation. Neuropsychopharmacology 40: 793-803.

Pedreira ME, Perez-Cuesta LM, Maldonado H. 2002. Reactivation and reconsolidation of long-term memory in the crab Chasmagnathus: protein synthesis requirement and mediation by NMDA-type glutamatergic receptors. J Neurosci 22: 8305-8311.

Pedreira ME, Prez-Cuesta LM, Maldonado H. 2004. Mismatch between what is expected and what actually occurs triggers memory reconsolidation or extinction. Learn Mem 11: 579-585.

Popper KR. 1963. Conjectures and refutations: the growth of scientific knowledge. Routledge and Kegan Paul, New York.

Przybyslawski J, Sara SJ. 1997. Reconsolidation of memory after its reactivation. Behav Brain Res 84: 241-246.

Rachman S. 1977. The conditioning theory of fear acquisition: a critical examination. Behav Res Ther 15: 375-387.

Robinson M, Franklin K. 2010. Reconsolidation of a morphine place preference: impact of the strength and age of memory on disruption by propranolol and midazolam. Behav Brain Res 213: 201-207.

Roozendaal B, McEwen BS, Chattarji S. 2009. Stress, memory and the amygdala. Nat Rev Neurosci 10: 423-433.

Schroyens N, Beckers T, Kindt M. 2017. In search for boundary conditions of reconsolidation: a failure of fear memory interference. Front Behav Neurosci 11: 65

Seligman ME. 1968. Chronic fear produced by unpredictable electric shock. $J$ Comp Physiol Psychol 66: 402-411.

Sevenster D, Beckers T, Kindt M. 2012. Retrieval per se is not sufficient to trigger reconsolidation of human fear memory. Neurobiol Learn Mem 97: $338-345$.

Sevenster D, Beckers T, Kindt M. 2013. Prediction error governs pharmacologically induced amnesia for learned fear. Science 339: 830-833.

Sevenster D, Beckers T, Kindt M. 2014. Prediction error demarcates the transition from retrieval, to reconsolidation, to new learning. Learn Mem 21: $580-584$. 
Shankman SA, Robison-Andrew EJ, Nelson BD, Altman SE, Campbell ML. 2011. Effects of predictability of shock timing and intensity on aversive responses. Int J Psychophysiol 80: 112-118.

Soeter M, Kindt M. 2010. Dissociating response systems: erasing fear from memory. Neurobiol Learn Mem 94: 30-41.

Soeter M, Kindt M. 2011. Noradrenergic enhancement of associative fear memory in humans. Neurobiol Learn Mem 96: 263-271.

Soeter M, Kindt M. 2012a. Erasing fear for an imagined threat event. Psychoneuroendocrinology 37: 1769-1779.

Soeter M, Kindt M. 2012b. Stimulation of the noradrenergic system during memory formation impairs extinction learning but not the disruption of reconsolidation. Neuropsychopharmacology 37: 1204-1215.

Soeter M, Kindt M. 2013. High trait anxiety: a challenge for disrupting fear memory reconsolidation. PLoS One 8: e75239.

Soeter M, Kindt M. 2015a. Retrieval cues that trigger reconsolidation of associative fear memory are not necessarily an exact replica of the original learning experience. Front Behav Neurosci 9: 122.

Soeter M, Kindt M. 2015b. An abrupt transformation of phobic behavior after a post-retrieval amnesic agent. Biol Psychiatry 78: 880-886.

Suzuki A, Josselyn SA, Frankland PW, Masushige S, Silva AJ, Kida S. 2004. Memory reconsolidation and extinction have distinct temporal and biochemical signatures. J Neurosci 24: 4787-4795.
Thompson A, Issakidis C, Hunt C. 2008. Delay to seek treatment for anxiety and mood disorders in an Australian clinical sample. Behav Change 25: 71-84.

Wang S, de Oliveira Alvares L, Nader K. 2009. Cellular and systems mechanisms of memory strength as a constraint on auditory fear reconsolidation. Nat Neurosci 12: 905-912.

Weaver IC, Cervoni N, Champagne FA, D'Alessio AC, Sharma S, Seckl JR, Dymov S, Szyf M, Meaney MJ. 2004. Epigenetic programming by maternal behavior. Nat Neurosci 7: 847-854.

Winters BD, Tucci MC, DaCosta-Furtado M. 2009. Older and stronger object memories are selectively destabilized by reactivation in the presence of new information. Learn Mem 16: 545-553.

Wood NE, Rosasco ML, Suris AM, Spring JD, Marin M, Lasko NB, Goetz JM, Fischer AM, Orr SP, Pitman RK. 2015. Pharmacological blockade of memory reconsolidation in posttraumatic stress disorder: three negative psychophysiological studies. Psychiatry Res 225: 31-39.

Zlomke K, Davis TE III. 2008. One-session treatment of specific phobias: a detailed description and review of treatment efficacy. Behav Ther 39: 207-223.

Received May 2, 2017; accepted in revised form June 30, 2017. 


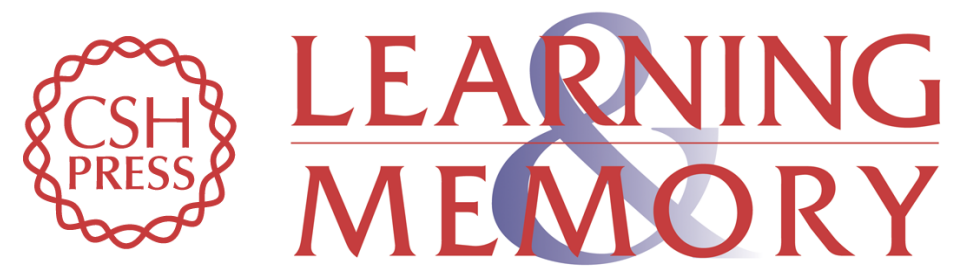

\section{Breaking boundaries: optimizing reconsolidation-based interventions for strong and old memories}

James W.B. Elsey and Merel Kindt

Learn. Mem. 2017, 24:

Access the most recent version at doi:10.1101/Im.044156.116

\begin{aligned} & \hline References $\begin{array}{l}\text { This article cites } 80 \text { articles, } 19 \text { of which can be accessed free at: } \\ \text { http://learnmem.cshlp.org/content/24/9/472.full.html\#ref-list-1 }\end{array} \\ & \begin{array}{r}\text { Creative } \\ \text { Commons } \\ \text { License }\end{array} \begin{array}{l}\text { This article is distributed exclusively by Cold Spring Harbor Laboratory Press for the } \\ \text { first } 12 \text { months after the full-issue publication date (see } \\ \text { http://learnmem.cshlp.org/site/misc/terms.xhtml). After } 12 \text { months, it is available under } \\ \text { a Creative Commons License (Attribution-NonCommercial } 4.0 \text { International), as } \\ \text { described at http://creativecommons.org/licenses/by-nc/4.0/. }\end{array} \\ & \begin{array}{c}\text { Receive free email alerts when new articles cite this article - sign up in the box at the } \\ \text { top right corner of the article or click here. }\end{array} \\ & \begin{array}{l}\text { Service } \\ \text { terting }\end{array}\end{aligned}$

